\title{
O produtivismo acadêmico na Pós-Graduação stricto sensu em Ciência da Informação no Brasil
}

\author{
The academic productivism in the Graduate Programs in Information Science in Brazil
}

\author{
Luciana Ferreira da Costa \\ Doutora em História e Filosofia da Ciência \\ Universidade Federal da Paraíba \\ lucianna.costa@yahoo.com.br \\ Edilson Teixeira Barbosa Filho \\ Graduando em Bibloteconomia \\ Universidade Federal da Paraíba \\ edilsonteixeira48@gmail.com
}

\begin{abstract}
Resumo
O produtivismo acadêmico, com origem nos Estados Unidos da América nos idos de 1950 e que, a partir de então, é globalmente conhecido pela máxima do publish or perish, configura-se como um fenômeno derivado dos processos de avaliação da pós-graduação, sendo caracterizado, portanto, pela excessiva ênfase na quantidade da produção científica. Tendo isso em conta, a presente pesquisa tem como objetivo analisar o impacto do produtivismo acadêmico na atividade desenvolvida pelos docentes vinculados aos Programas de Pós-Graduação em Ciência da Informação no Brasil, com ênfase nos programas em funcionamento nas regiões Norte, Nordeste e Centro-oeste do país. A partir disso, a pesquisa traça o perfil dos docentes do núcleo permanente dos programas; descreve a percepção dos docentes sobre o produtivismo acadêmico; identifica os impactos do produtivismo acadêmico na trajetória dos docentes. Para tanto, a pesquisa é de caráter bibliográfico, documental e descritivo, ancorada na abordagem qualitativa com aporte quantitativo. A coleta de dados se dá por meio da aplicação de questionário, com dados tratados a partir da análise de conteúdo. Os resultados indicam de que o grupo investigado, em sua maioria, reconhece as exigências e a ênfase no quantitativo da produção científica e o impacto da lógica produtivista no seu modo de vida, confirmando que o produtivismo pode afetar não só o trabalho, mas também acarretar problemas de saúde como ansiedade, estresse e a síndrome de Burnout. Conclui que que esse fenômeno do produtivismo acadêmico é inerente à pós-graduação e que suas consequências vêm afetando o trabalho, a pesquisa, a saúde e o modo de viver dos docentes, algo talvez agravado, ainda mais, pela pandemia da COVID-19 e a necessidade do distanciamento físico.
\end{abstract}

\section{Palavras-chave}

Produtivismo acadêmico. Ciência da Informação. Programa de Pós-graduação em Ciência da Informação. Universidade pública. Brasil.

\begin{abstract}
The academic productivism, which originated in the United States of America in the 1950's and is since then globally known by the maxim of publish or perish, is configured as a phenomenon derived from the postgraduate evaluation processes, being characterized, therefore, by excessive emphasis on the quantity of scientific production. Taking this into account, this research aims to analyze the impact of academic productivism on the activities developed by professors linked to the Graduate Programs in Information Science in Brazil, emphasizing the ongoing programs in the North, Northeast


and Center-West regions of the country. Based on this, the research traces the profile of permanente professors of the programs; describes the perception of the professors about academic productivism and identifies the impacts of academic productivism on their trajectory. To this end, this research nature is bibliographic, documentary and descriptive, anchored in the qualitative approach with quantitative contribution. The data collection is done through the application of a questionnaire, with data processed from the analysis of content. The results reveal that the majority of the investigated group recognizes the demands and emphasis on the quantitative aspect of scientific production and the impact of the productivist logic on their way of living, confirming that the productivism can affect not only the work, but can also cause health problems such as anxiety, stress and the Burnout syndrome. It concludes that this phenomenon of academic productivism is inherent to graduate school and that its consequences have affected the work, research, health and way of life of professors, which is perhaps further aggravated by the pandemic of COVID-19 and the need for physical distance.

\section{Keywords}

Academic productivism. Information Science. Graduate Program in Information Science. Public university. Brazil.

\section{CONTEXTUALIZAÇÃO INICIAL}

A pesquisa em relato ${ }^{1}$ objetivou analisar o impacto do produtivismo acadêmico na atividade de docentes vinculados aos Programas de Pós-Graduação em Ciência da Informação no Brasil, com ênfase nos programas existentes nas regiões Norte, Nordeste e Centrooeste do país.

Na sociedade contemporânea, o conhecimento científico, convertido em capital intelectual, vem ganhando cada vez mais destaque, sendo esse produzido, essencialmente, nas instituições públicas de ensino superior no Brasil por meio da pesquisa acadêmica. Objetivando impulsionar a produção desse conhecimento, o aparelho estatal e as agências de fomento estabelecem critérios de avaliação que priorizam a quantidade das publicações. Como consequência, a produção do conhecimento está submetida ao modelo fabril e se aproxima, cada vez mais, do status de mercadoria. Nesse cenário, a pesquisa acadêmica que antes parecia protegida desse fenômeno similar ao Fordismo, é vítima da precarização. Os docentes acumulam inúmeras funções, frustrações e adoecem para ganhar cada vez mais pontos em uma corrida de quem produz mais. Tendo em mente os agravantes ocasionados por esse fenômeno que vem se naturalizando no meio acadêmico, estudiosos de diversas áreas se debruçam sobre a temática do produtivismo acadêmico. Esses estudiosos descortinam em suas publicações resultados de pesquisas que apontam as consequências do fenômeno produtivismo acadêmico - que assola, especialmente, a pós-graduação no Brasil e no mundo.

Os Programas de Pós-Graduação (PPG) são considerados loci privilegiados de práticas científicas, produção de conhecimento e formação de alto nível (VELLOSO; VELHO, 2001), daí a motivação em pesquisar a temática produtivismo acadêmico na área da Ciência da Informação, no contexto dos PPG. Tendo isso em conta, a problemática norteadora da pesquisa em relato foi definida pela seguinte pergunta: qual o impacto do produtivismo acadêmico na atividade desenvolvida por docentes no âmbito dos Programas de Pós-Graduação em Ciência da Informação das regiões norte, nordeste e centro-oeste do Brasil? Revelou-se instigante analisar o impacto do produtivismo acadêmico nesta área de conhecimento, dado o reco-

\footnotetext{
${ }^{1}$ Realizada no âmbito do Programa Institucional de Bolsa de Iniciação Científica (PIBIC) da Universidade Federal da Paraíba (UFPB), conforme Edital 02/2019, PVE10992-2019, PIBIC-UFPB-CNPq (2019-2020).
} 
nhecimento do papel dos PPG para conferir impulso teórico e conceitual para a área, já que é amplamente reconhecido que as pesquisas inovadoras se desenvolvem fundamentalmente no âmbito da pós-graduação.

No presente estudo, de modo a conhecer os docentes atuantes nos PPG, delineou-se o perfil do grupo investigado. Em continuidade, evidenciou-se a percepção dos docentes sobre o produtivismo acadêmico e, por fim, desvelou-se, a partir do discurso dos docentes, o impacto do produtivismo acadêmico em suas trajetórias.

\section{O FENÔMENO DO PRODUTIVISMO ACADÊMICO}

O termo produtivismo acadêmico, também conhecido como performatividade acadêmica (ALCADIPANI, 2011), propagou-se nos Estados Unidos da América (EUA) na década de 1950 por meio da expressão "Publish or perish" (publicar ou perecer), citada pela primeira vez em 1932, sendo, a partir de então, adotada no meio acadêmico. Essa expressão, que enfatiza a publicação como objetivo final do trabalho intelectual (ALVES, 2014), demonstra o risco que intelectuais, cientistas e acadêmicos corriam se não cumprissem as metas impostas pelos órgãos de financiamento, pelas universidades e pelo mercado.

De acordo com Renata Curty (2010), o lema publish or perish é o símbolo da pressão social para que intelectuais, cientistas e acadêmicos publiquem cada vez mais, e seu decanto é também um símbolo de decadência visível da universidade como instituição do saber, onde o pensamento reflexivo e competente é substituído pelo culto à produtividade sem critérios.

No Brasil, a adoção do produtivismo acadêmico remete ao final dos anos 1970 e, de forma legitimada, aos anos 1990 (GODOI; XAVIER, 2012). Rememora-se, acerca disso, uma polêmica reportagem publicada no jornal Folha de São Paulo, em fevereiro de 1988, que divulgou o que ficou conhecida como "a lista dos improdutivos". A lista foi elaborada com base na relação de 1.108 de 4.398 professores da Universidade de São Paulo (USP) que não apresentaram produções científicas nos anos de 1985 e $1986^{2}$. Este fato colocou a produção docente como pauta em reflexões e debates intelectuais (SAMPAIO, 2016).

Baseando-se nesse fato, questiona-se: qual a importância de escrever e publicar? Publicar resultados e contribuir para o crescimento e compartilhamento do conhecimento científico, bem como para colaborar com a qualidade de vida dos indivíduos e com o desenvolvimento do país, parece uma resposta óbvia, mas que, apesar de óbvia, não garante que as pesquisas desenvolvidas e publicadas possuam qualidade ou relevância. A pressão por publicar faz com que, por vezes, os pesquisadores lancem mão de práticas antiéticas para atingir o quantitativo ideal para serem bem qualificados e se manterem "produtivos".

A pesquisa é a dimensão mais prestigiada entre as demais - ensino, extensão e gestão - que compõem o trabalho docente, sobretudo no contexto das universidades públicas. Esse prestígio se deve às contribuições que o capital intelectual trouxe para os sistemas produtivos, fazendo com que os professores pesquisadores ganhassem maior visibilidade social (NÓVOA, 2007; VOSGUERAU; ORLANDO; MEYER, 2017). Em contrapartida, é a partir da pesquisa que as universidades e os docentes envolvidos nessa atividade são avaliados. A constante reinvenção de formas de avaliação da pós-graduação intensifica o trabalho dos profes-

\footnotetext{
2 Elaborada pela Reitoria da USP, continha nomes de pesquisadores da própria instituição que não teriam publicado nenhum trabalho científico no citado arco cronológico. Alguns anos depois, precisamente em maio de 1995, o mesmo jornal apresentou a reportagem "A lista dos produtivos", que continha os nomes de 170 pesquisadores brasileiros com mais de 200 citações no Science Citation Index (SCI).
} 
sores pesquisadores, promovendo um cenário de exclusão, alienação e estranhamento no trabalho a partir de processos de avaliação que se baseiam em critérios quantitativos de produção acadêmica (SGUISSARD, SILVA JÚNIOR, 2009; VIZEU; MACADAR, GRAEML, 2014).

Para Kuenzer e Morais (2005), o novo modelo de avaliação valoriza prioritariamente a produção científica, provocando o deslocamento da centralidade na docência para a centralidade na pesquisa. Apesar de reconhecerem o caráter positivo da centralidade na pesquisa no âmbito da pós-graduação, os autores pontuam alguns aspectos negativos e não resolvidos do novo modelo, como a "ausência de uma fórmula razoável e rápida para avaliar a qualidade da produção científica em termos de impacto social e científico dos produtos na qualidade de vida" e também a situação do "“surto produtivista" em que a quantidade se institui em meta e o que conta é publicar" reverberando na "banalização de formas legítimas de produção" (KUENZER; MORAIS, 2005, p.1348).

Nas palavras de Pimenta (2014, p. 158) "é a produção de saberes reduzida à corrida por publicação e aos pontos que gerar." A autora discute que o sistema de avalição da pósgraduação é basicamente alicerçado sobre as publicações. Ao analisar os documentos de área para sua tese, Pimenta concluiu que esse "ranking" torna as relações entre os docentes mais competitivas e ansiosas, uma vez que a permanência dos professores nos PPG depende dos pontos somados no Lattes durante o triênio de avaliação. Nesse sentido, as metas estabelecidas geram pressão hierarquizada no âmbito da pós-graduação, onde as pró-reitorias de pesquisa e pós-graduação são pressionadas pela Coordenação de Aperfeiçoamento de Pessoal de Nível Superior (CAPES), que por sua vez exercem pressão nos coordenadores, que cobram a produção do corpo docente para garantir uma boa pontuação no sistema de avaliação (CAFÉ, 2017). Ademais, a pressão imposta por prazos curtos que não consideram as distintas áreas do conhecimento, suas especificidades e os diferentes contextos nas quais as produções acadêmicas são produzidas, acabam por comprometer, também, o trato dado sobre questões teóricas da pesquisa (WARDER, 2013 apud GUILL; ZANFERARI; ALMEIDA, 2017).

Conceituando produtivismo acadêmico, Trein e Rodrigues (2011) o concebem como, a partir de sua materialização em artigos, como "fetiche-conhecimento-mercadoria" que contribui para o "mal-estar" da academia brasileira. Na perspectiva de Rego (2014), o produtivismo acadêmico é encarado como a obrigação do pesquisador para publicar, quase que exclusivamente, em periódicos a fim de ser avaliado, já que as publicações nas revistas geram indicadores de qualidade do pesquisador, apesar da relevância questionável das publicações. Já para Camargo Jr. (2014), esse fenômeno se caracteriza pela pressão exercida junto aos pesquisadores para publicar sempre e cada vez mais. Essa obrigação por produzir pode chegar a níveis insustentáveis e insuportáveis, impactando negativamente não só a qualidade das publicações, mas a vida e a saúde dos profissionais acometidos por esse fenômeno.

Em sua obra intitulada Produção intelectual no ambiente acadêmico, Renata Curty (2010, p. 34) disserta sobre a tônica da sociedade contemporânea: "publicar a qualquer custo, publicar seja lá o que for, publicar como forma de sobrevivência profissional" e acredita que, em nome de pretensa otimização da produtividade, a ascensão profissional obedece a parâmetros cada vez mais quantitativos. Indo além, a autora acredita que é inevitável que a ênfase no quantitativo, em se tratando da produção intelectual e científica, acentua o desvirtuamento das universidades

Mas afinal, qual a origem desse ciclo "anômalo" e como ele se mantém operante? Ao tentar responder tal pergunta, depara-se com diversos estudos que apontam para o modelo de avaliação das agências de fomento como um dos principais fatores para propagação do 
"surto produtivista". Sobre a avaliação, Curty (2010, p. 60) acredita que "na academia o consenso sobre a necessidade da avaliação, como processo contínuo, pode ser unânime", mas adverte que esta unanimidade é insustentável por não considerar as especificidades de cada área do conhecimento, sendo vigente o estabelecimento de "critérios únicos e unitários para avaliar programas e produções tão distintos".

Em suma, para melhor compreensão da influência da lógica produtivista no âmbito da pós-graduação é preciso refletir sobre o método de avaliação das agências de fomento a partir da ótica de estudiosos que se dedicam a refletir sobre o produtivismo acadêmico e seus impactos.

\subsection{Agências de fomento e o método de avaliação dos programas de pós-graduação}

A CAPES vem sendo criticada por sua proposta de avaliação, que passou por mudança em seus critérios a partir dos anos 1996-1997 (MATTOS, 2008). Essas mudanças dizem respeito a intensificação dos critérios quantitativos como parâmetros para avaliação dos cursos de mestrado e doutorado em todas as áreas de conhecimento (SGUISSARD, 2010), afetando especialmente as universidades públicas onde, no Brasil, encontra-se a maioria dos PPG.

De acordo com Moreira (2009), o processo de conhecimento é transformado em mercadoria pela avaliação da CAPES, desse modo contribuindo para que o desempenho dos docentes seja medido pelo produto final. Em linha com o exposto, destaca-se a investigação de Alessandra Pimenta (2014) sobre os efeitos do positivismo nos professores/pesquisadores na área de educação, onde a autora evidencia a ausência de parâmetros específicos para a avaliação de outros cursos, reforçando, portanto, a afirmativa de Sguissard (2010) sobre os critérios de avaliação dos PPG independente da área. Como fruto desses processos de regulação, controle e gerenciamento, chamados de avaliação, temos o produtivismo acadêmico (SGUISSARD, 2010; ROSA, 2008).

O modelo avaliativo é norteado pelo quantitativo das produções científicas, fazendo com que a colocação dos cursos seja determinada, praticamente, pelo número de publicações qualisadas ${ }^{3}$ que somou, caracterizando, desse modo, potencialmente um produtivismo acadêmico vazio de conteúdo e de significado. Segundo a autora, o grande problema em relação aos documentos de área em meio a grande quantidade de normas e requisitos para o credenciamento, é um sistema de avaliação totalmente normatizado operante dentro do modelo produtivista ao qual os docentes têm que se submeter (PIMENTA, 2014).

Vale salientar que essas discussões não são contra a existência das agências de fomento, uma vez que a pesquisa no Brasil depende de financiamento público, mas sim contra a política de avaliação neoliberal ancorada no produtivismo (PIMENTA, 2014). O caráter essencial da CAPES é inegável, conforme destacam diversos estudos, e que há conquistas inquestionáveis na existência de um processo de avaliação, como a regulamentação de aspectos ou quesitos pertinentes em relação à pesquisa, definição de duração máxima dos cursos de pós-graduação, aprimoramento das orientações, entre outros (BIANCHETTI; VALLE; PEREIRA, 2015; COSTA, 2017; VOSGERAU; ORLANDO; MEYER, 2017).

Apesar das críticas ao fenômeno do produtivismo acadêmico, existem argumentos favoráveis ao mesmo e ao modelo de avaliação da CAPES, entre eles o de Machado (2007,

\footnotetext{
${ }^{3}$ É fato que apesar de acreditar-se que a classificação dos veículos de divulgação por meio do Qualis para periódicos, ainda que incipiente, busca construir padrões mínimos de qualidade e permite em alguma medida enfrentar o surto produtivista (KUENZER, MORAES, 2005).
} 
p.140), segundo o qual a agência vem trabalhando por uma pujante cultura de pesquisas e de publicações, algo que o autor considera justificado pela necessidade de "que os trabalhos dos pesquisadores apareçam no espaço público. Ainda na perspectiva de Machado, as exigências quanto à publicação por parte dos pesquisadores estão em compasso com a lógica básica do movimento da ciência, precisando ser compreendida, aceita e praticada, dado que os investimentos de recursos públicos não devem ser desperdiçados e que os resultados das pesquisas retornem como benefícios para sociedade.

Sobre isso, Patrus, Dantas e Shigaki (2015) refletem que os argumentos favoráveis às cobranças por publicação defendem o princípio de tornar público o resultado das pesquisas, sobretudo as realizadas com recursos públicos e a elevação da pesquisa brasileira ao patamar internacional. Dito isso, os autores advertem que a ausência de um modelo de avaliação provocaria maior prejuízo que eventuais efeitos colaterais produzidos pelo sistema. O produtivismo acadêmico é visto, nessa perspectiva, como um desses efeitos.

Nota-se, pelo exposto, a preocupação para que a pesquisa no Brasil se aproxime dos padrões internacionais de excelência acadêmica como uma das justificativas para a defesa das cobranças do modelo quantitativo de avaliação das agências de fomento. Em relação à internacionalização, um dos quesitos de avaliação dos PPG, Hostins (2006, p. 151) aponta que "para impulsionar a internacionalização é necessário induzir os programas à competitividade, à inovação e ao empreendedorismo, tal como funciona a lógica do setor corporativo empresarial". Todavia, segundo Oliveira, no prefácio da obra de Sguissard e Silva Júnior (2009), é necessário considerar que o Brasil "[...] é um país 'tardio', capitalismo tardio, independência tardia, abolição [da escravidão] tardia, industrialização tardia e... universidade tardia" (OLIVEIRA, 2009, p. 12).

Foi a partir da queda do regime ditatorial e da retomada do processo democrático que a educação formal brasileira se expandiu, o que ocorreu em 1985 pela institucionalização da Nova República, e da aprovação da nova Constituição Federal do país (1988) e da LDBEN no 9394/96 (BIANCHETTI; VALLE, 2014). Conforme aponta Bianchetti (2009), foi nesse contexto de expansão, em meados de 1990, que os PPG passaram a ser submetidos, na sua forma de gestão, avaliação e financiamento. As mudanças de caráter indutivo, como a redução do tempo para conclusão das dissertações e teses; a submissão de todas as áreas do conhecimento ao mesmo padrão de avaliação; a transformação dos cursos em programas; a submissão do financiamento à avaliação, com previsão de recompensas ou punições em número de bolsas e taxas de auxílio; a mudança nos objetivos da CAPES, priorizando a formação de pesquisadores ao invés de professores e a ampliação do espectro de atuação da CAPES que aumenta o número de responsabilidades da mesma, afetaram os pesquisadores e a qualidade da produção do conhecimento (BIANCHETTI; VALLE, 2014).

Com base nas ponderações dos autores, é possível notar que as consequências da proposta de avaliação da capes não passam despercebidas. Para Kuenzer e Morais $(2005$, p. 1350), é necessário "avaliar a avaliação", buscando novos formatos que avancem para além dos resultados conseguidos e superem os limites do modelo em curso.

Por fim, é importante ressaltar também que o produtivismo não deve ser elencado como único responsável por todas as mazelas do modelo de avaliação com ênfase na produção científica, pois conforme Kuhlmann Jr. (2015) tomar o produtivismo como único determinante dos impactos negativos na saúde dos docentes é simplificar o modo de avaliação das condições de trabalho, enevoando questões como os baixos salários, as más condições de trabalho em sala de aula, entre outros fatores. Considera-se, obviamente, que esses agravantes não devem ser ignorados, mas sim discutidos à luz das pesquisas científicas. 


\subsection{As consequências do produtivismo acadêmico}

Apesar do termo datar da década de 1950, o produtivismo acadêmico vem se mostrando uma das frentes de pesquisa contemporâneas, tendo suas dimensões críticas vastamente investigadas e discutidas por pesquisadores brasileiros e estrangeiros. Em termos cronológicos, os estudos sobre essa temática são relativamente recentes, com maior concentração de publicações a partir do ano de 2010 (PATRUS; DANTAS; SHIGAKI, 2015), devido a recorrência dos efeitos negativos atrelados a esse fenômeno que assolam a produção científica acadêmica na pós-graduação (SGUISSARDI; SILVA JÚNIOR, 2009).

De acordo com Trein e Rodrigues (2011, p. 778), a corrida para produzir cada vez mais reflete em uma competitividade entre pesquisadores que precisam demonstrar sua "capacidade técnica" de produção através do volume de sua produção anterior e previsão dos produtos resultantes da investigação. As autoras supracitadas alertam para a forma quase-industrial que os métodos de organização do trabalho científico estão seguindo, na qual os consórcios de pesquisa deverão prever os "produtos inovadores" que precisarão emergir de seu trabalho coletivo, seguindo a equação ideológica em que a ciência se deve desdobrar em tecnologia, que deve produzir inovações, que por sua vez contribuem para o desenvolvimento econômico, que levará ao desenvolvimento social.

Em seu artigo sobre a ética no trabalho acadêmico, Vizeu, Macadar e Graeml (2016), afirmam que a pressão imposta pela demanda quantitativa de produção afeta um professorpesquisador tanto quanto uma pessoa de negócios, corroborando com a proposição de Sguissardi e Silva Júnior (2009) sobre mercantilização da universidade pública. Para os autores citados, o governo, a partir de uma perspectiva neoliberal, reduziu o compromisso político com as universidades, enquanto que o discurso economista na educação com foco em metas, eficiência e produtividade, ganhou força, o que ensejou o crescimento da pressão exercida pelo modelo produtivista em pesquisadores, que por vezes resulta em um comportamento oportunista.

O que se instala, então, é uma cultura de individualismo, competição e rivalidade, própria da globalização do trabalho, na qual a sensação de pertencimento, a junção de esforços e o trabalho em conjunto em prol de um objetivo comum dão vez a soma de desempenhos individuais (SANTOS, 2010; BORSOI, 2012; PATRUS; DANTAS; SHIGAKI, 2015). O conceito de solidariedade acadêmica, ameaçado pela competição, derivada do produtivismo, "tende a corroer a noção de pertinência a esse sistema, prejudicando a consciência da necessidade de coesão e de cooperação entre pares" (PATRUS; DANTAS; SHIGAKI, 2015, p. 1418). Mas, conforme acreditam Patrus, Dantas e Shigaki (2015), trata-se de um cenário que pode mudar com a cooperação e solidariedade dos pesquisadores, podendo melhorar muito se a avaliação da CAPES analisar o corpo docente permanente e não a soma dos seus membros.

Nesse sentido, ao criticarem o produtivismo acadêmico, Bianchetti, Valle e Pereira (2015, p. 86) citam a ausência, a conformidade e as poucas formas de resistência dos acadêmicos, e que o produtivismo acadêmico implica no "fim da categoria dos intelectuais na acepção clássica do termo". Os intelectuais são substituídos por funcionários produtivos, intelectuais institucionalizados, focados apenas em suas respectivas especialidades e disciplinas. Por outro lado, parte dos professores e intelectuais das universidades desenvolveu forte resistência, em nome da liberdade acadêmica e da defesa da educação liberal, não atrelada a fins econômicos utilitários e pragmáticos (PIMENTA, 2014). 
Os impactos negativos desse fenômeno também podem ser notados no processo de formação dos professores. Como citado anteriormente, houve mudança nos objetivos da CAPES: da formação de professores para o ensino superior à formação de pesquisadores. Essas mudanças interferiram fortemente na dinâmica da pós-graduação a ponto de provocar uma mudança paradigmática na pós-graduação brasileira (KUENZER; MORAES, 2005). Pimenta (2014) perpassa por questões referentes à formação dos professores, que devido as mudanças de objetivos citadas anteriormente, a didática e o ensino ficam em segundo plano em relação à pesquisa, influenciando também no processo de seleção de profissionais para atuarem no ensino superior, onde o currículo tem um peso maior que a didática. O processo de mercantilização da universidade estatal pública brasileira é um fenômeno que super qualifica a pós-graduação enquanto desqualifica a graduação e a prática docente (SGUISSARDI; SILVA JÚNIOR, 2009). Como reflexos dessas políticas mercantis, as instituições de ensino superior se afastam, cada vez mais, dessa identidade; a didática e o ensino ficam em segundo plano, e nota-se a proliferação de doutores focados na produção de resultados, já que são valorizados em suas respectivas áreas de atuação por critérios quantitativos (VOSGUERAU; ORLANDO; MEYER, 2017).

Em seu a artigo intitulado Da liberdade à "gaiola de cristal", Andrade, Cassundé e Barbosa (2019), apontam para perda do componente criativo, a liberdade, antes presente na prática do trabalho docente, agora preso em uma "gaiola de cristal"4 pelo critério de avaliação do modelo produtivista, onde a autonomia acadêmica e docente passaram a ser limitadas e reguladas por agências de fomento e avaliação (SANTIAGO; CARVALHO; 2008, 2011; SANTIAGO; CARVALHO; FERREIRA, 2015 apud ANDRADE; CASSUNDÉ; BARBOSA, 2019). Em vista disso, a universidade vai aos poucos e de maneira sutil, transformando seu papel social da liberdade de produção, autonomia e formação crítica do cidadão, à gaiola de cristal.

Ainda sobre as consequências decorrentes do produtivismo, é imprescindível falar sobre algo já abordado por pesquisadores como Bianchetti e Machado (2009): a intensificação do trabalho docente. $O$ docente que atua nas instituições de ensino superior ${ }^{5}$ acumula funções além da docência, o que resulta em uma intensa rotina de atividades precípuas de toda universidade: ensino, pesquisa e extensão (BOSI, 2007), ao que acrescentamos a atividade de gestão (no âmbito do Colegiado Departamental, do PPG, ou à frente de alguma unidade administrativa vinculada à instituição em que atuam). Além das citadas anteriormente, os docentes por vezes chegam a exercer outras atividades fora do expediente, onde as tecnologias da informação e comunicação invadem o espaço-tempo desses profissionais, cerceando o tempo livre, sobrecarregando-os (BORSOI, 2012; YAMAMOTO et al., 2012; LEITE, 2017). Somado a esse acumulo de funções, a demanda por produção por parte dos docentes com os parâmetros quantitativos de avaliação estabelecidos pelas agências de fomento, resultam em consequências físicas e psicoemocionais que afligem o trabalhador-pesquisador, a ponto de vulnerabilizar a saúde desses profissionais (BORSOI, 2012; PIMENTA, 2014; RIBEIRO; LEDA; SILVA, 2015; LEITE, 2017).

Deve-se atentar, também, ao perigo que esse sistema reflete na trajetória dos discentes, que dão seus primeiros passos na pesquisa ou que almejam seguir a carreira docente. De acordo com Alcadipani (2011), há o perigo de que esses discentes encarem a produ-

\footnotetext{
${ }^{4}$ Termo cunhado por Santiago e Ferreira em 2012.

${ }^{5}$ Os autores entendem que esta particularidade se mostra muito mais presente nas universidades públicas. É fato que parcela dos docentes no Brasil atuam em instituições privadas e, portanto, não estão, necessariamente, sob as exigências do produtivismo acadêmico. Embora, essa condição não quer dizer que os docentes das instituições de ensino superior privadas não sofrem os efeitos da precarização do trabalho.
} 
ção acadêmica como um fim em si mesmo, onde a publicação é o produto final do processo de pesquisa. Segundo Wood Júnior (2016, p. 132), em entrevista para a revista Adusp, "novas gerações de pesquisadores, mestrandos e doutorandos [...] dão mais importância as publicações e suas recompensas, [...] e menos atenção ao conhecimento e sua aplicação na sociedade". Esse comportamento resulta no que Godoi e Xavier (2012) chamam de (de)formação na produção da nova geração de pesquisadores e, como atestado por Curty (2010), distancia a pesquisa acadêmica do seu real propósito, onde em "um mundo ideal", o objetivo dessa atividade é o de compartilhar as descobertas científicas de modo que contribuam para o avanço do conhecimento e, consequentemente, gerem impactos positivos no que tange o desenvolvimento da sociedade. Porém, o objetivo sob a ótica produtivista se mostra outro: alimentar o curriculum, almejando financiamento, manutenção de bolsas, aprovação em concursos, avaliações positivas e status, decorrente disto (PAULA, 2012). Desse modo, é conferido ao processo de avaliação uma natureza meritocrática, aproximando-se cada vez mais da "máquina de fazer pontos" (GODOI; XAVIER, 2012), ou máquina do produtivismo (WATERS, 2006).

Em suma, com base nos estudos de diversos teóricos, o novo modelo de avaliação e a pressão ocasionada pelo produtivismo trouxeram uma série de consequências além das já citadas anteriormente, entre as quais destacam-se também as publicações requentadas ou maquiadas, repetidas exaustivamente em nome da quantificação por meio de artifícios que vão da mudança de título, acréscimo de autores, alteração de palavras introdutórias e assim por diante (KUENZER, MORAES, 2005; CURTY, 2010; YAMAMOTO et al., 2012). Nessa mesma linha, outras consequências são a fraude acadêmica, o plágio, o autoplágio (TREIN; RODRIGUES, 2011). Não se pode ignorar, também, a precarização do trabalho docente e seus aspectos como as condições de trabalho e contrato existentes (geralmente precárias); a mercantilização das atividades de ensino, pesquisa e extensão nas instituições de ensino superior; e, como atestado anteriormente, a adoção de critérios exclusivamente quantitativos para avaliação do trabalho docente (BOSI, 2007; BORSOI, 2012; RIBEIRO; LEDA, SILVA, 2015). Os prejuízos vão além da ética e do comprometimento da qualidade da produção intelectual, afetando a saúde física e psicoemocional dos pesquisadores (BIANCHETTI, MACHADO, 2009; BORSOI, 2012; RIBEIRO; LEDA; SILVA, 2015; LEITE, 2017).

A partir desse quadro reflexivo sobre o fenômeno do produtivismo acadêmico, podese concluir que este é um fator que atrapalha a formação, atuação, saúde e ética dos docentes submetidos a esse modelo mercantil de produção do conhecimento, chegando ao ponto de que os profissionais expostos a tais condições sejam acometidos pela insatisfação com a profissão, pela falta de motivação e pelo mal-estar que pode levar a síndrome de Burnot, que se caracteriza pela exaustão prolongada e a diminuição do interesse em trabalhar, e até mesmo ao abandono da carreira (PIMENTA, 2014).

\section{PARÂMETROS METODOLOGICOS}

Considerando que a pesquisa em relato teve como objetivo analisar o impacto do produtivismo acadêmico na atividade desenvolvida pelos docentes vinculados no âmbito dos Programas de Pós-Graduação em Ciência da Informação das regiões norte, nordeste e centro-oeste do Brasil, a pesquisa possui natureza bibliográfica, documental e descritiva, sob abordagem qualitativa com aporte quantitativo.

Compuseram os sujeitos da pesquisa os docentes do núcleo permanente dos PPG em Ciência da Informação que determinou o universo de 104 docentes. Os dados sobre os do- 
centes foram obtidos por meio de acesso aos sites dos PPG. De posse dados acessou-se o Currículo Lattes de cada um dos 104 docentes permanentes para delineamento do perfil e identificação de atividades exercidas pelo grupo investigado.

Em termos de PPG, fizeram parte da pesquisa oito programas das regiões norte, nordeste e centro-oeste, a saber: Programa de Pós-Graduação em Ciência da Informação da Universidade Federal do Pará (PPGCl/UFPA); Programa de Pós-Graduação em Ciência da Informação da Universidade Federal da Bahia (PPGCI/UFBA); Programa de Pós-Graduação em Ciência da Informação da Universidade Federal de Sergipe (PPGCI/UFS); Programa de PósGraduação em Ciência da Informação da Universidade Federal da Paraíba (PPGCI/UFPB); Programa de Pós-Graduação em Ciência da Informação da Universidade Federal de Alagoas (PPGCI/UFAL); Programa de Pós-Graduação em Ciência da Informação da Universidade Federal de Pernambuco (PPGCI/UFPE); Programa de Pós-Graduação em Ciência da Informação da Universidade Federal do Ceará (PPGCI/UFC); Programa de Pós-Graduação em Ciência da Informação da Universidade de Brasília (PPGCINF/UnB).

Para a coleta de dados, utilizou-se de questionário com a finalidade de averiguar o conhecimento do grupo investigado acerca do produtivismo acadêmico, bem como o impacto desse fenômeno em suas atividades. O questionário, composto por nove questões, foi elaborado no Google Forms, com Termo de Consentimento Livre e Esclarecido pela opção ou não de participar da pesquisa em relato, e encaminhado aos docentes no mês de maio de 2020, com preenchimento em torno de sete minutos. Garantiu-se a confidencialidade e o anonimato dos dados, tratados única e exclusivamente para fins científicos, evitando a exposição do perfil dos respondentes e qualquer cruzamento de dados que possa revelar suas identidades.

A organização dos dados se deu em planilhas e o tratamento dos dados se deu pela utilização de estatística básica descritiva.

Como método de análise, utilizou-se a Análise de conteúdo (BARDIN, 1977), empregando a análise categorial. Esta consiste em operações de desmembramento do texto em categorias agrupadas analogicamente com objetivo de descobrir os núcleos de sentido que compõe uma comunicação. A opção por este método se deu pelo fato de que se constituiu adequado para estudar opiniões, crenças e valores por meio de dados qualitativos. Assim, o modelo de análise foi construído com base nas perguntas norteadoras agrupadas em quatro categorias principais, definidas de acordo com o objetivo geral e específicos da pesquisa em relato e o aporte teórico, que também é usado como definições. Conseguinte, definiram-se as dimensões, as fontes e o instrumento de coleta responsável por atender as categorias de análise: a) importância de atuar em um PPG; b) Percepção acerca do modelo de avaliação da CAPES; c) Produtivismo acadêmico; d) Impactos e consequências da lógica produtivista.

\section{APRESENTAÇÃO E DISCUSSÃO DOS RESULTADOS}

Nesta apresentam-se a caracterização dos docentes, mediante dados obtidos no Currículo Lattes, no que diz respeito à formação acadêmica, temas de interesse, liderança de grupo de pesquisa, atividade de orientação de dissertação e tese, e, por fim, participação como membro de corpo editorial de periódicos científicos. Por sua vez, em sequência, apresentam-se discussões quanto ao fenômeno do produtivismo acadêmico.

\subsection{Caracterização dos docentes permanentes dos PPG em Ciência da Informação}


No que tange a formação acadêmica, constatou-se que a formação graduada do grupo investigado é composta por 43 cursos de graduação, com predomínio de formação na área das Ciências Sociais Aplicadas (39\%), seguida da área de Ciências Exatas (30\%), Ciências Humanas (23\%) e outras (8\%). Dos docentes investigados, observou-se que 17 registraram possuir mais de uma graduação e apenas um docente não apresentou graduação em seu Currículo Lattes. Apesar da grande variedade de áreas nas graduações, levantou-se que a formação graduada em Biblioteconomia apareceu com maior incidência, 61 ocorrências, seguida por História com 11 ocorrências. As outras graduações chegam no máximo em seis ocorrências.

Assim como na graduação, a formação em nível de mestrado apresentou uma grande variedade de cursos. Identificou-se que 98 (94\%) dos 104 docentes realizaram curso de mestrado. Os demais, no caso três docentes, não realizaram curso de mestrado e realizaram o doutorado após a graduação, enquanto apenas um docente realizou dois cursos de mestrado. Ciência da Informação é o curso de mestrado com maior ocorrência, 33 (33\%), seguido de Educação com 9 (9\%) e Biblioteconomia com 7 (7\%), os demais cursos chegam a no máximo 4 ocorrências.

Uma vez que a titulação de doutorado é requisito básico para vinculação a qualquer programa de pós-graduação stricto sensu no Brasil para atuar como docente, os 104 docentes dos PPG em Ciência da Informação são detentores do título de Doutor, desse total, apenas dois docentes possuem mais de um doutorado. O doutorado em Ciência da Informação se mostra como o mais incidente, com um total de 50 ocorrências, sendo os docentes da UnB e UFPB com maior incidência de doutorado nessa área.

Como último aspecto, no que diz respeito ao pós-doutorado (estágio de pesquisa), identificou-se que 28 (26\%) docentes realizaram estágio pós-doutoral. A UFPE apresenta o maior número de docentes com pós-doutorado, total de três, seguida pela UFPB, UFPA e UnB com dois docentes cada, a UFBA e a UFC apresentam um docente cada, enquanto a FUFSE e a UFAL não apresentam nenhum docente com pós-doutorado. Dentre os docentes que realizaram estágio pós-doutoral, evidenciou-se que dois docentes realizaram mais de um pós-doutorado.

Em despeito à categoria de liderança em grupos de pesquisa, os dados coletados no Currículo Lattes foram cruzados com as informações do DGP do CNPq com intuito de confirmar os dados informados pelos docentes em seus currículos. Como resultado, 84 (80\%) docentes do grupo investigado exercem liderança de grupo de pesquisa. Destaca-se que alguns docentes lideram mais de um grupo de pesquisa, além de participarem em outros grupos na condição de membro pesquisador.

Em seguida, buscou-se identificar no currículo dos docentes as atividades de orientação de dissertação e tese em conclusão e/ou em andamento. Do total, apenas dois docentes não constavam com atividades de orientação em seus currículos, enquanto os outros apresentaram algum tipo de orientação. ${ }^{6}$

A última categoria diz respeito à participação dos docentes permanentes como membro do corpo editorial de periódicos científicos. Identificou-se que 89 (85\%) dos docentes pertencem ao corpo editorial de periódicos científicos. Considerando que a maioria dos docentes é membro do corpo editorial de mais de um periódico, identificaram-se 205 periódicos diferentes registrados nos Currículos Lattes do grupo investigado. A maior concentração está em cinco periódicos da área da Ciência da Informação, a saber: Informação \& Soci-

\footnotetext{
${ }^{6}$ Nesta categoria não se considerou orientação de trabalho de conclusão de curso, uma vez que essa pesquisa tem como cerne o âmbito dos PPG e suas atividades.
} 
edade: estudos, TransInformação, Ciência da Informação, Informação em Pauta, Em Questão e Revista Digital de Biblioteconomia.

Apresentados e discutidos os dados obtidos por meio do Currículo Lattes dos docentes dos PPG em Cl, descrevem-se, a partir de agora, os resultados da aplicação do questionário que foi respondido por 38 docentes $^{7}$. Portanto, é o que se aplica ao que será exposto e discutido em sequência. Dito isso, a faixa etária do grupo respondente se apresenta distribuído da seguinte forma: $3 \%$ entre $31-35$ anos; $8 \%$ entre $36-40$ anos; $23 \%$ entre $41-45$ anos; $8 \%$ entre 46-50 anos. A maioria, correspondente a $62 \%(F=23)$, possuem mais de 51 anos de idade.

Quanto ao tempo de vínculo com a universidade, obteve-se que 34\% dos docentes atuam na IFES entre 4 e 10 anos; 57\% atuam entre 11 e 30 anos; 5\% atuam entre 31 e 39 anos; $2 \%$ possuem vinculação há 40 anos. Já o tempo de vínculo com seus respectivos PPG demonstrou que a maioria, $73 \%$, possui vínculo entre um e 10 anos, enquanto que $23 \%$ possuem vínculo entre 11 e 16 anos. Apenas 2\% têm vínculo há 35 anos.

\subsection{Sobre a importância de atuar em um Programa de Pós-Graduação}

Quanto a importância de atuar em um PPG, os docentes poderiam elencar um a três aspectos sobre isso. Constatou-se que os respondentes elencaram, com maior frequência, exigência de atuar em um PPG para participação em editais das agências de fomento. Outras questões como produtividade científica, e visibilidade do pesquisador também foram elencadas, conforme algumas respostas em destaque:

\section{[...] alguns editais de fomento exigem a vinculação a algum PPG. (D.22)}

\section{[...] oportunidades para concorrer em projetos/financiamentos em agências de} fomento. (D.34)

Mais tempo para dedicar à pesquisa, mais possibilidades de financiamento, maior visibilidade do pesquisador. (D.30)

Extremo aumento de produtividade acadêmica verticalizada [...], incremento de produtividade quantitativa e qualitativa do grupo de pesquisa sob minha liderança. (D.3)

As respostas supracitadas dialogam com a problemática da pesquisa. $O$ destaque para a vinculação a um PPG para a participação em editais das agências de fomento, coadunam com a reflexão de que a ciência passível de interesse acarreta na aceleração da produção científica, e as pesquisas que podem receber financiamento, caracterizando a dinâmica na qual o trabalho intelectual e seus resultados são submetidos ao modelo mercantil aos interesses do capital, onde a quantidade tem um peso maior que a qualidade e o conhecimento é convertido em capital (SGUISSARD, SILVA JÚNIOR, 2009; TREIN; RODRIGUES, 2011; SGUISSARDI, 2010; PIMENTA, 2014; FERREIRA; MIRANDA; GURGEL, 2016).

\footnotetext{
${ }^{7}$ Os autores esclarecem que o período de aplicação do questionário se deu, justamente, no momento em que o mundo foi atingido pela pandemia de COVID-19 que afetou sobremaneira as condições e o volume de trabalho dos docentes. Para além disso, a amostra de 38 respondentes, o equivalente a $40 \%$, mostra-se aceitável dada a pouca variabilidade em que não é necessária uma amostra maior ou igual ao universo, devido a informação muito concreta de que o que foi investigado é um fenômeno bem homogêneo, além do cerne da pesquisa ter sido tratado sob a ótica qualitativa.
} 
Reflete-se, ainda, que o elenco dos aspectos exigência de atuar em um PPG para participação em editais das agências de fomento. Outras questões como produtividade científica, e visibilidade do pesquisador podem ser considerados um indicativo de como os docentes estão submetidos ao modelo quantitativo de avaliação das agências de fomento. Entretanto é imprescindível asseverar que nas instituições públicas o financiamento é fundamental para manutenção e continuidade das instituições e, consequentemente, dos PPG.

Identificou-se outro aspecto da importância de atuar em um PPG, a partir dos docentes, a colaboração com a formação e orientação de futuros pesquisadores, segundo as respostas em sequência:

Colaborar com a formação acadêmica de futuros pesquisadores na área [...]. (D.4)

Formar pessoal qualificado [...]. (D.15)

Contribuir para os pós-graduandos com minha experiência [...]. (D.2)

[...] Continuidade de orientação de discentes desde a graduação [...]. (D.9)

Acerca disso, ao considerar um ambiente por vezes competitivo e individualista que resulta do produtivismo acadêmico, reflete-se que os pesquisadores em formação, expostos a essa cultura produtivista de rivalidade e competição, podem vir a se tornarem futuros profissionais acometidos pelo fenômeno do produtivismo, dado que o currículo tem um peso maior na seleção de profissionais para atuarem no ensino superior. Influenciados, também, por um processo de formação que prioriza a formação de pesquisadores e não de docentes, os aspectos negativos desse processo podem refletir na qualidade da atuação desses futuros profissionais tanto na produção de conhecimento quanto na docência (KUENZER, MORAES, 2005). Ainda no âmbito da importância de atuar em um PPG, constatou-se que foi elencada a relação ensino e pesquisa nas seguintes respostas: Melhorar as aulas por meio das pesquisas (D. 9) e Maior proximidade entre ensino e pesquisa (D. 31).

\subsubsection{Conhecimento sobre os Documentos de Área da CAPES}

Quanto ao conhecimento dos Documentos de Área que registram critérios e diretrizes de avaliação de um PPG, a maioria dos docentes investigados, o equivalente a 27 docentes afirmou possuir total conhecimento do referido documento e das exigências de atuar em um programa antes de se credenciarem. Alguns docentes atribuíram o conhecimento a realização de pesquisas que tiveram como objeto de estudo essa questão e outros por terem por experiência na elaboração de propostas de seus respectivos programas. Evidenciou-se, ainda, uma pequena parcela dos docentes que afirmaram não ter conhecimento ou ter conhecimento parcial dos Documentos de Áreas e das demandas de um PPG.

\subsection{Percepção acerca do modelo de avaliação da CAPES}

Quanto a percepção do modelo de avaliação dos PPG por parte da CAPES, a partir das respostas dos docentes é possível perceber três aspectos: tendencioso, ênfase na quantidade e não na qualidade e produtivista: 


\begin{abstract}
Um pouco tendenciosa, no sentido de criar critérios que em alguns casos deprecia o trabalho de um PPG que se esforça para manter um nível de qualidade. (D.4)

Parece-nos que estão sublimando a quantidade em detrimento da qualidade da produção científica (D.13)

Distante da realidade de relevância das pesquisas - avalia números apenas. (D.35)
\end{abstract}

Enfatiza os dados quantitativos produtivistas. (D.29)

Acho uma escravidão à publicação. (D.37)

Acredita-se, com base nas respostas supracitadas, que a maioria dos docentes não concordam com o modelo de avaliação da CAPES, centrado na quantidade. Contudo, alguns dos respondentes consideram a avaliação necessária e pertinente, mas passível de adequação e aprimoramento, como se vê a seguir:

Necessário, porém com aspectos injustos, a exemplo de prestigiar excessivamente a produção científica. (D.17)

Satisfatório, mas podendo melhorar. As informações são muito específicas, que, penso, não reverbera adequadamente em melhorias aos PPG. Outro ponto corresponde ao estímulo perverso à produção científica, o que, pare$c e$, estar adoecendo muitos docentes, incentivando o autoplágio. (D.19)

O modelo é bastante exaustivo, mas faz-se necessário tantas informações, a partir do momento em que se avaliam cursos brasileiros e que deve-se ter parâmetros para julgamentos. (D.18)

Os aspectos avaliados se mostram pertinentes, mas há uma instabilidade nas formas de aprimoramento e na aplicação do instrumento de avaliação. (D.34)

Por conseguinte, um dos docentes se posicionou em defesa de critérios ainda mais rigorosos por parte da CAPES na avaliação dos PPG, afirmando que: Deveria ser bem mais rígido com os programas, é muito fácil atingir a pontuação necessária. (D.20).

É fato que, por uma questão ética, a avaliação é substancial em termos éticos e de prestação de contas por parte dos docentes que recebem financiamento para realização de suas pesquisas, e é unânime o consenso sobre a necessidade da avaliação como processo contínuo (CURTY, 2010). A avaliação também é responsável por aumentar o ingresso de discentes na Pós-Graduação, ampliando assim o número de mestres e doutores detentores de bolsas de pesquisa (BIANCHETTI; MACHADO, 2007). Todavia, o modelo de avaliação atual é pautado na produtividade, onde é substancial produzir em grande quantidade para atingir as metas estabelecidas, gerando uma pressão hierarquizada na pós-graduação exercida sobre o corpo docente para garantia de boa pontuação do programa na avaliação (CAFÉ, 2017).

Os canais de comunicação científica em que os docentes de um PPG veiculam sua produção científica são avaliados e recebem estratos de classificação, como já foi citado nesta pesquisa: o Qualis periódicos, que busca trazer parâmetros qualitativos para o sistema de avaliação, como expresso na seguinte resposta: 
[...] a Plataforma Sucupira ainda não conta com verificadores do quantitativo de adoções ou citações das produções coletadas, utilizando como exclusivo critério de qualificação a Classificação QUALIS [...]. (D.3)

No entanto, retomando Kuenzer, Moraes (2005) e Curty (2010), ainda não existe uma fórmula razoável e rápida para avaliar a produção científica quanto ao seu impacto social e científico, já que o vigente sistema de avalição da CAPES apresenta critérios frágeis insuficientes para medir a evolução da qualidade da produção científica.

É necessário haver um equilibrio no que concerne aos critérios avaliativos. Porém, no tocante a produtividade docente considero demasiado exigente $\boldsymbol{e}$ ultrapassa os limites humanos de dedicação ao tempo de produção, atentando aspectos quantitativos em detrimento dos qualitativos. (D.36)

O exposto está em linha com a constatação de Andrade, Cassundé e Barbosa (2019) que afirmam - com base nos dados de sua pesquisa - que é necessária uma melhor distribuição do peso entre as atividades desenvolvidas na pós-graduação. Com base nos estudos de Café, Ribeiro e Ponczek (2017), entendemos que os moldes do sistema de avaliação, a pesquisa científica publicada em periódicos qualificados é mais enfatizada que as outras atividades realizadas pelos docentes, influenciando mais do que essas atividades, tanto para entrada quanto na permanência de cursos no Sistema Nacional de Pós-Graduação (SNPG).

Por fim, outras respostas que corroboram com as anteriores no tocante ao modelo de avaliação da CAPES e mencionam no que isso reverbera como o fenômeno produtivista marcado pela competição, rivalidade e falta de solidariedade:

Em sua maioria são modelos que incentivam a competição desnecessária. Uma espécie de salve-se quem puder. Vale quem produz mais. (D.12)

Em grande medida equivocado, porque vem, cada vez mais, priorizando dados estatísticos em detrimento de aspectos humanos e sociais; porque se ampara em posicionamentos de concorrência - muitas vezes desleais - entre os programas; porque avalia produção em série, com critérios pouco sofisticados para se saber o que difere uma produção de qualidade de algumas muitas vezes "requentadas". (D.8)

Nesse sentido, esses fatores cooperam para a manutenção da cultura do individualismo, competição e rivalidade já abordadas anteriormente. A afirmação de que "vale mais quem produz" confirma os achados de Santos (2010), Borsoi (2012), Patrus, Dantas e Shigaki (2015) no sentido de que a individualidade vai ocupando o espaço da colaboração e junção de esforços, aspectos elencados como importantes na atuação em um PPG pelos próprios respondentes desta pesquisa em relato.

\subsection{Entendimento do produtivismo acadêmico}

Sintetizando em termos simples as definições do produtivismo acadêmico trazidas no aporte teórico, compreendemos que, fruto de uma lógica neoliberal, esse fenômeno é entendido como a ênfase excessiva no quantitativo de produção acadêmica e científica em detrimento da qualidade, tendo a publicação como objetivo final do trabalho intelectual (ALVES, 2014; CAMARGO JR., 2014; PIMENTA, 2014; REGO, 2014). Ao analisar as respostas dos respondentes, destacamos algumas que ilustram essa definição: 
É a valorização excessiva da produtividade e produção científica publicada em livros, periódicos, anais, etc., deixando para segundo plano os aspectos qualitativos desta mesma produção. (D.36)

Excesso valor na quantidade da produção acadêmica e pouca consideração quanto a sua qualidade, apesar da avaliação pelos pares. (D.21)

Tem se direcionado para a cobrança excessiva de produção, focando cada vez mais na quantidade e menos na qualidade. (D.34)

À medida que as respostas foram analisadas, cada vez mais a incidência das palavras quantidade e qualidade se fizeram presentes:

A necessidade de alcançar números de publicações em detrimento a qualidade. (D.35)

Valorização numérica em detrimento da qualidade. (D.27)

Quantidade acima de qualidade. (D.9)

Apesar de curtas, as respostas exprimem os aspectos atrelados ao surto produtivista: a quantidade em detrimento da qualidade. Já se tem conhecimento que a busca desenfreada pelo aumento da quantidade de produção compromete a qualidade da pesquisa desenvolvida na academia de modo geral, nesse sentido, os docentes se posicionaram da seguinte forma:

O produtivismo acadêmico, a meu ver, se constitui na prática acadêmicocientífica que tem como principal objetivo o "crescimento" da produção, independente de outras variáveis indispensáveis à qualidade dessa produção como, por exemplo, "aderência", "relevância", "inovação", "continuidade" e "aplicação", entre outras. (D.38)

Entendo como a produção voltada para resultados quantitativos (quantidade de publicações), embora nem sempre seja acompanhada de resultados qualitativos consistentes, que se revertam no avanço do conhecimento. (D.22)

Em conjunto com os demais, os relatos acima reavaliam o entendimento de autores como Alcadipani (2011), Bianchetti e Valle (2014) sobre a preocupação com a qualidade das produções. Para Alcadipani (2011), a produção de artigos em escala quase industrial pode resultar em artigos de baixa qualidade e com pouca relevância ou benefício acadêmico e social.

Ratificando o apontamento de Alves (2014), Camargo Jr. (2014), Pimenta (2014) e Rego (2014), a resposta a seguir reforçam o entendimento de que a lógica mercantil tem a publicação como objetivo final do trabalho intelectual a fim de garantir pontos em um ranking competitivo para permanecer produtivo: Produzir, para competir, para ser avaliado $e$ atingir as metas, sem atuar nas suas áreas de interesse e excesso de produção. (D.25)

Não raro, o tempo de maturação das pesquisas, que difere dependendo da área do conhecimento a qual se encaixa, é por vezes comprometido devido aos curtos prazos e a cobrança por produção. O posicionamento a seguir ratifica o entendimento de Warder (2013) sobre a qualidade duvidosa das pesquisas por conta do tempo que demanda o trato teórico: 
Acho uma cobrança exagerada, permitindo a produção de trabalhos que nem sempre retratam o esforço do pesquisador, pois o tempo de maturação de uma pesquisa, em muitos casos precisam de algum tempo para que tenha qualidade. (D.4)

Em consonância com os posicionamentos, autores como Trein, Rodrigues (2011), Vosguerau, Orlando e Meyer (2017), dialogam sobre a forma quase-industrial nas quais as publicações passam a se enquadrar para atender as demandas do capital, corroborando para o afastamento da identidade de instituição de saber e que, nesse contexto, passam a formar futuros docentes e pesquisadores focados na produção de resultados:

\begin{abstract}
A gana por produção em série; $\boldsymbol{a}$ industrialização do pensar acadêmico; $\boldsymbol{a}$ supremacia da quantidade pela qualidade e a morte desta quando o foco é o pensar crítica e de modo complexo os fenômenos contemporâneos. Por fim - mas apenas para diminuir a enorme lista de possibilidades - o produtivismo acadêmico é uma ideologia de desmonte do pensamento crítico, que funciona como a alimentação homeopática dos discursos orquestrados para o desmonte das pesquisas nas IFES, principalmente, e delas próprias como instituições científicas. (D.8)
\end{abstract}

Uma forma de percepção distorcida sobre o que deve ser a atividade docente e de produção de conhecimento científico, pautada na incorporação da lógica do mercado como modelo a ser seguido no campo científico. (D.28)

As assertivas selecionadas até então corroboram com as proposições de Curty (2010) sobre a limitação da racionalidade crítica e o cerceamento da criação e criatividade causadas pelo culto a produtividade sem critérios. É preciso retomar os critérios de qualidade ao centro da temática produção intelectual, científica e acadêmica.

Caberiam, aqui, outras das tantas respostas dadas pelos docentes que definem bem a lógica produtivista e conversam com os autores citados anteriormente. Até então, o método de avaliação das agências de fomento vem sendo apontado como um dos principais indicadores da manutenção e propagação do produtivismo acadêmico. De modo similar as respostas sobre a percepção do sistema de avaliação da CAPES, os participantes voltam a citar os instrumentos de avaliação e seus indicadores quantitativos:

A cobrança/valorização por/de uma quantidade de produção exacerbada para atender critérios de órgãos de fomento como a CAPES. (D.30)

A forma encontrada pelas agências de fomento de impor aos pesquisadores a lógica de prestigiar a quantidade da produção acadêmica em detrimento da qualidade dessa produção. (D.17)

Não menos importante, há docentes favoráveis à lógica produtivista, com destaque para a seguinte consideração: Algo muito normal e natural, não entendo como uma pessoa estuda tanto a nível de doutorado para não seguir pesquisando e atuando como pesquisador. (D.20)

Como dito anteriormente nesta pesquisa, as discussões sobre o tema produtivismo acadêmico são polêmicas e ensejam diversos pontos de vista. O posicionamento do docente favorável à lógica produtivista está em linha com Machado (2007) quando este refletiu que se trata de uma lógica básica do movimento da ciência que precisa ser aceita e praticada já que as pesquisas recebem investimentos de recursos públicos. Entretanto, é substancial re- 
conhecer que as discussões sobre esse fenômeno são válidas, uma vez que produtividade e produtivismo são questões distintas. Porém, nota-se que os docentes com posicionamentos favoráveis não compreendem o produtivismo da maneira que ele vem sendo pautado nas pesquisas que discutem o tema: algo negativo que impacta o trabalho e, por vezes, a vida pessoal dos profissionais que são forçados a atuar dentro dessa lógica mercantil de produção do conhecimento intelectual. Portanto, as próximas categorias de análise são fundamentais para entender a dimensão negativa desse fenômeno a partir da ótica daqueles que são impactados pelo mesmo.

\subsection{Impactos e consequências da lógica produtivista}

Dando continuidade à análise, os docentes foram questionados sobre o impacto da lógica produtivista na qualidade de suas atividades (aulas, orientação, produção intelectual, participação em eventos, avaliação de artigos para periódicos, etc.), de modo a se conhecer melhor as consequências disso no labor dos sujeitos dessa pesquisa. Algo percebido na seguinte resposta: [O produtivismo acadêmico] é composto por uma série de indicadores que vão deste a produção de artigos até a formação dos orientandos. (D.16)

É de suma importância reconhecer que, além de mudar o modus operandi de realizar pesquisa, o produtivismo também se caracteriza pelo acúmulo de funções por parte dos docentes (CURTY, 2010). Rememorando os dados coletados sobre as atividades realizadas pelos docentes, observou-se que $80 \%$ deles atuam como líderes de um ou mais grupos de pesquisa, que $85 \%$ são membros do corpo editorial de periódicos, e apenas dois não apresentaram atividade de orientação de tese e dissertação. Apesar de essas serem exigências conferidas a qualquer docente vinculado a um PPG, deve-se considerar que, com a pressão imposta por produzir e mostrar resultado, as atividades acumuladas tendem por intensificar o trabalho docente. Esse contexto pode ser observado nas seguintes respostas:

Inegavelmente [o produtivismo acadêmico] impacta. Somos cobrados por publicar, então se você está preocupado com a qualidade do que publica, invariavelmente tem de dedicar mais tempo e energia para a pesquisa, em detrimento da preparação de aulas, por exemplo. (D.22)

[...] embora no Plano Individual Docente (PID) o docente só possa contabilizar 40 horas semanais, a jornada de trabalho docente excede em muito do que essas $\mathbf{4 0}$ horas e consome finais de semana, feriados, recessos... Além da preparação de aulas, pesquisas, orientações de TCC, dissertação, tese, pesquisas de iniciação científica, os docentes produzem artigos e/ou capítulos, trabalhos em eventos, avaliam artigos, participam de comissões de seleção de concursos... São inúmeras as atividades docentes. (D.11)

[...] a cobrança do produtivismo faz com que o pesquisador acabe por passar muito mais horas do que as "ditas" $\mathbf{4 0}$ horas semanais em seu trabaIho. Invadindo finais de semana, feriados, recessos e quarentenas [...]. (D.30)

Assim como mostra o relato acima, o conjunto de atividades para além da pesquisa chega, por vezes, despendam tempo na carga horária de 40 horas semanais, resultando em uma sobrecarga de trabalho: 
Na medida do possível vamos conciliando todas estas atividades. Uma aula, uma orientação a um aluno de graduação ou de pós, não pode ser prejudicada em função de outros afazeres. O caso é que "temos que dar conta" e não raramente estamos trabalhando praticamente o dia todo, 7 dias por semana para cumprir nossos objetivos. (D.18)

Sim, impacta em todas as atividades, visto que é preciso orientar, ensinar, produzir e realizar serviços administrativos. Não dá para fazer tudo bem. (D.31)

Geralmente, o docente que atua na pós-graduação acumula as mesmas atividades nos cursos de graduação. Logicamente, exerce uma sobrecarga que impacta na qualidade das atividades. (D.6)

Partindo do pressuposto de que, de acordo com Borsoi (2012), o trabalho docente é imaterial por excelência, tanto os relatos já expostos quanto os seguintes ilustram como o trabalho docente realizado dentro e fora do ambiente acadêmico extrapola os limites específicos da jornada de trabalho:

Eu já nem sei se esse prolongamento do tempo-espaço na vida dos professores é uma consequência deste tempo ou se não o já era em priscas eras. No entanto, condeno quaisquer ideias e pensamentos de que isso é ou deva ser uma ação "missionária" do professor [...]. (D.8)

Por mais que busquemos não invadir nosso espaço-tempo pessoal, a auto cobrança e a cobrança pela produtividade, atrelada aos diversos papeis sociais que todos desempenhamos, interfere na qualidade do nosso tempo livre. Não há feriados ou finais de semana ou mesmo recessos e nem horários definidos para o trabalho. Este acontece a todo momento, dentro e fora dos espaços acadêmicos. A pandemia [COVID-19] $]^{8}$ e o distanciamento social são exemplos desta realidade, onde o uso do tempo para produtividade continuou e até mesmo aumentou e o espaço-tempo ultrapassa de vez a barreira academia-casa. (D.36)

O uso das tecnologias da informação e comunicação (TIC) são otimizadoras da extensão da academia, pois basta um celular e/ou uma conexão com a Internet para que o espaço-tempo desses profissionais seja invadido, sobrecarregando-os ainda mais (BORSOI, 2012; YAMAMOTO et al., 2012; LEITE, 2017) e submetendo-os a um modo de viver onde não se reconhece mais limites entre o tempo de trabalho e o tempo de não trabalho (BORSOI, 2012).

Observa-se que o produtivismo compromete também a qualidade das outras atividades referidas. Retomando o pensamento de Borsoi (2012) os parâmetros de produtividade e a diversidade de atividades que transitam entre as exigências do investimento intelectual em pesquisas, artigos, etc. e as exigências burocráticas, impactam tanto a qualidade da produção científica quanto a saúde e o modo de viver dos docentes.

Em resumo, a maioria das respostas dos docentes retoma a possível queda da qualidade das produções intelectuais por conta do produtivismo. Assim, como atesta Borsoi (2012), percebe-se a preocupação por parte dos docentes com a perda do caráter acadêmico

\footnotetext{
${ }^{8} \mathrm{~A}$ doença do coronavírus (COVID-19) é uma doença infecciosa causada por um coronavírus recém-descoberto, conforme disponível em: https://covid.saude.gov.br/.
} 
e social da produção científica, já que a relevância está no impacto quantitativo no currículo do docente e não na relevância da pesquisa em si:

Sim, impacta na qualidade da produção porque exige que o pesquisador publique determinado número de produção ao ano e isso faz com que o pesquisador se preocupe em cumprir a meta da produção em detrimento da preocupação com uma maior qualidade. (D.11)

Sou vigilante e procuro evitar os possíveis impactos negativos oriundos dessa lógica, mas percebo que há uma tendência para que os resultados auferidos na pós-graduação estejam, em grande medida, dissociados da qualidade. (D.10)

Ao final, há em meio as respostas aquelas que merecem destaque nesta categoria de análise, por reafirmarem e/ou expandirem aspectos atestados nas demais categorias préestabelecidas:

Sim [impacta], por conta do tempo que exige. Não me atinge pq não tenho produção excessiva, aliás, para os critérios da Capes, apesar de trabalhar muito, sou considerada improdutiva pq tenho muito projeto, mas nem sempre público (uma publicação ao ano). (D.2)

É uma lógica suicida do todo da vida acadêmica e científica dos professores pesquisadores. Ela se assenta na produção histérica, cretina e mecânica, desfazendo toda e qualquer possibilidade de pensarmos e agirmos no "mundo das coisas" como laboratório exemplar de vida e aferição desta. É a lógica do desmonte das salas de aula como laboratórios perceptivos, cognitivos, de percepção em devir. (D.8)

As respostas referidas acima reafirmam a necessidade de retomar a valorização de outras atividades, a exemplo do ensino, extensão, orientação e formação de futuros pesquisadores, a fim de equalizar o peso dos parâmetros de avaliação estabelecidos pelas próprias agências financiadoras e também as agências reguladoras do trabalho acadêmico (CURTY, 2010, PAULA, 2012). Nesse aspecto, retoma-se a proposição de Godoi e Xavier (2012) sobre a "máquina de fazer pontos" que é o produtivismo acadêmico, onde dentro dessa lógica, a produtividade do docente de modo geral não é tão considerada - valendo menos pontos enquanto o número de publicações em revistas com Qualis de referência soma mais pontos no resultado final. A "ganância" por pontos torna o cenário cada vez mais competitivo:

[...] por vezes, nos sentimos "enganados" por outros conhecidos pesquisadores que driblam esse sistema de produtivismo repetindo o mesmo artigo várias vezes, com poucas e singelas modificações em diversos periódicos, para poder cumprir metas estabelecidas, sem a menor preocupação com ética, originalidade ou qualidade. (D.30)

Mais uma vez as questões sobre ética e a qualidade das pesquisas emergem nas discussões sobre o produtivismo. Destaca-se outra resposta em compasso com os estudos de Vizeu, Macadar e Graeml (2016) sobre o comportamento oportunista adotado pelos pesquisadores para garantir um alto número de publicações: 
[...] Caso o docente saiba lidar artesanalmente com sua baixa produção $e$ saiba driblar critérios qualitativos de submissão aos eventos científicos, periódicos e tais, será muito mais valorizado pelo produtivismo do que pela produção, sem, contudo, fazer uma contribuição relevante [...] um único artigo, comunicação ou monografia muitas vezes citado, contribuiu mais para a ciência do que muitos artigos repetitivos e pouco adotados ou citados. (D.3)

Comportamentos oportunistas e práticas antiéticas geram um ambiente de ansiedade e competitividade entre os profissionais que ameaça o conceito de solidariedade acadêmica (PATRUS, DANTAS, SHIGAKI, 2015). Esse comportamento pode afetar também os discentes em processo de formação que, envoltos pela cultura produtivista, podem lançar mão do plágio em suas pesquisas, enxergando-as como produto final do processo intelectual que os rende recompensas, como um diploma e a carreira no ensino superior (ALCADIPANI, 2011; WOOD JR., 2016), ao que Godoi e Xavier (2012) percebem como (de)formação na produção da nova geração de pesquisadores. A resposta adiante retrata esta questão:

Numa ocasião, cheguei a descobrir uma página inteira de minha tese de doutorado publicada no corpo de um artigo aprovado e publicado nos anais da ANPUH. Ou seja, passa a ser nosso dever verificar todo e qualquer texto acadêmico, em qualquer nível. Em nosso colegiado, estamos discutindo a assinatura de aplicativos potentes de combate ao plágio, vamos assumir pessoalmente essa despesa. É triste demais a situação da academia, creio que seja em âmbito mundial. (D.3)

Ainda assim, o comprometimento da ética e da moral e a qualidade das publicações não se limitam como únicas ou principais consequências ocasionadas pela lógica mercantil a qual a pesquisa acadêmica tem sido forçada. Notam-se indícios de consequências para além do mundo laboral. Estresse, saúde mental e qualidade de vida, são termos cada vez mais recorrentes em estudos sobre esse fenômeno. É notável a preocupação com a dimensão psicoemocional vulnerabilizada pelas anomalias advindas da máquina produtivista. Então, a fim de reforçar e verificar as consequências atestadas por autores como Bianchetti, Machado (2009), Godoi, Xavier (2012), Leite (2017), entre outros, evidenciam-se as seguintes respostas:

[...] Essa discussão envolve outras questões negativas importantes de serem discutidas, como a competitividade excessiva, baixa qualidade de vida, stress, entre outros. (D.26)

Com certeza a lógica da produtividade exagerada implica diretamente no tempo necessário para se dedicar a outras atividades acadêmicas e também na própria qualidade de vida, muitas vezes, interferindo no rendimento $e$ na saúde mental. (D.36)

Sobre o adoecimento docente, é possível extrair das respostas trechos sobre o estresse ocasionado pelo produtivismo que reafirmam os apontamentos de autores como Borsoi (2012), Ribeiro, Leda, Silva (2015) e Leite (2017) a respeito da vulnerabilização da saúde dos docentes e o cerceamento do tempo livre dedicado ao convício social e familiar:

Por conta das inúmeras atividades, o docente que atua, sob pressão, para atender as demandas, invadem o seu tempo destinado ao convívio social. 


\section{Esse espaço-tempo invadido passa a fazer parte da sua rotina ocasionando estresse e distanciamento familiar. (D.6)}

[...] O trabalho do professor de pós-graduação tende a ser contínuo e incessante, invadindo todo o espaço-tempo do docente. $O$ resultado é o estresse e dificuldades no convívio social. (D.10)

Entre os respondentes há aqueles que enfrentaram problemas de saúde e sofrimentos psíquicos, como a síndrome de burnout que corresponde a uma síndrome do trabalho, associada nos estudos de Pimenta (2014) ao produtivismo acadêmico:

Tenho trabalhado todo dia, nem sei mais o que é final de semana, férias ou feriados. Trabalho em casa, na universidade, em todo lugar. Estou viciada em trabalho e doente.

[...] Cumpro com muita responsabilidade as minhas atribuições, sempre disposto a colaborar com o Programa e com os discentes. Mas hoje não barganho (informo com muita sinceridade) o meu final de semana, em estar com pessoas realmente importantes para mim, minha família e amigos. Depois de adoecer (sofri por muito tempo a síndrome de burnout), relativizei bastante a minha postura acadêmica, e hoje não corroboro com professores 'desesperados' em produção. Minha produção científica é regular, e satisfatória. (D.25)

Ademais, o segundo relato acima também convida a refletir as ponderações de Bianchetti, Valle e Pereira (2015), que atestam sobre a conformidade dos acadêmicos que são reduzidos a funcionários produtivos, ou meras engrenagens na máquina do produtivismo (WATERS, 2006).

[...] É uma lógica que precisa ser refutada, mas, a mim me parece que a maioria virou uma manada de seres obedientes à histeria da produção agônica e fria, em detrimento do hedonismo da pesquisa, que liberta e alegra, sem roubar de nós a visão crítica do mundo e de seus fenômenos. (D.8)

Em linhas de síntese das análises e discussões, sobre esta resposta, percebe-se seu alinhamento com as reflexões de Waters (2006) e também com Pimenta (2014), reafirmando a necessidade de buscar formas de resistir a lógica produtivista e atestando que essa resistência passa a surgir entre os intelectuais.

\section{CONSIDERAÇÕES FINAIS}

A presente pesquisa teve como objetivo analisar o impacto do produtivismo acadêmico na atividade dos docentes vinculados aos Programas de Pós-Graduação em Ciências da Informação das regiões Norte, Nordeste e Centro-oeste do Brasil.

A partir dos dados coletados no Currículo Lattes de cada docente foi possível identificar que o grupo investigado exerce inúmeras atividades para além da pesquisa científica, como orientação, editoração de periódicos científicos e liderança de grupo de pesquisa. Por meio desta investigação, evidenciou-se que essas e outras atividades, como a docência, são prejudicadas pela pressão por "produtividade", confirmando também a intensificação das 
atividades atribuídas aos docentes que extrapolam a jornada de trabalho na instituição, invadindo o tempo livre e os finais de semana.

Nesse sentido, é fato que a grande quantidade de atividades em conjunto com a demanda por produzir sempre mais é um dos principais motivos que podem levar os docentes a não conseguirem realizar todas as atividades em tempo hábil e com a dedicação necessária.

Nota-se que, embora os docentes investigados reconheçam a importância do sistema de avaliação da CAPES, consideram-no como um dos principais motivos para manutenção do produtivismo acadêmico. Desse modo, a qualidade e o trato teórico das pesquisas são por vezes comprometidas por conta dos parâmetros quantitativos de avaliação que fazem com que o número de publicações seja mais valorizado que a relevância das publicações em si. Ademais, os participantes reconhecem que os prazos são curtos para o tempo de maturação necessário para algumas pesquisas, e que tais prazos desconsideram especificidades dos distintos temas e contextos de produção intelectual. Ainda sobre os critérios avaliativos das agências de fomento e avaliação, é possível notar a insatisfação quanto a ausência de equilíbrio entre os critérios que faz com que outras atividades realizadas no âmbito da PósGraduação tenham menos valor em relação à pesquisa científica, fazendo com que certos docentes sejam considerados "improdutivos" apesar de exercerem tantas outras funções.

A partir dos relatos sobre o impacto da lógica produtivista no modo de viver dos docentes, confirmou-se que o produtivismo pode afetar não só o trabalho, mas também acarretar problemas de saúde como ansiedade, estresse e a síndrome de burnout. Ao relacionar os resultados obtidos com os estudos realizados por outros autores que discorrem sobre esse fenômeno, é possível notar a similaridade entre os resultados.

$\mathrm{Na}$ esteira dessa problemática, compreende-se que os resultados aqui encontrados não diferem dos já atestados nos estudos de campo que serviram de inspiração e fundamentação para a presente pesquisa, confirmando-os e mostrando que esse fenômeno é inerente à pós-graduação e suas consequências afetam o trabalho, a pesquisa, a saúde e o modo de viver dos docentes, no caso desta pesquisa os vinculados aos Programas de Pós-Graduação em Ciência da Informação.

Espera-se que os resultados aqui apresentados tragam uma mais valia para a área de conhecimento da Ciência da Informação, para a sua comunidade científica, para sua sociedade científica, bem como para as agências reguladoras e decisórias no âmbito da Ciência e Tecnologia no Brasil, como a Coordenação de Aperfeiçoamento de Pessoal de Nível Superior (CAPES) e o Conselho Nacional de Desenvolvimento Científico e Tecnológico (CNPq), no que diz respeito às informações que norteiam o planejamento e avaliação dos programas de pós-graduação, bem como para as discussões acerca dessa temática que não se esgotam aqui. Tanto que os autores darão continuidade à pesquisa, agora contemplando os Programas de Pós-Graduação em Ciência da Informação das regiões Sul e Sudeste do Brasil

À guisa de conclusões, compreendemos que, além de necessárias, as pesquisas sobre o produtivismo acadêmico se apresentam como forma de resistência ao propor reflexões acerca da intensificação do trabalho docente, da precarização do trabalho, entre tantos outros problemas ocasionados pelo fenômeno do produtivismo acadêmico decorrente dos modelos quantitativos de avaliação. O controle cada vez mais rígido do processo do fazer científico e do trabalho docente adotado pelos mecanismos de avaliação, tornam o fazer docente e a vivência na academia um trabalho mecânico, fazendo com que a criatividade e a liberdade, por vezes, retomando as palavras de Andrade, Cassundé e Barbosa (2019), estejam presas em uma "gaiola de cristal". 


\section{AGRADECIMENTOS}

Ao Conselho Nacional de Desenvolvimento Científico e Tecnológico (CNPq) e à Pró-Reitoria de Pesquisa (PROPESQ) da Universidade Federal da Paraíba (UFPB), no âmbito do Programa Institucional de Bolsa de Iniciação Científica (PIBIC), pelo financiamento da pesquisa. Aos docentes permanentes dos Programas de Pós-Graduação em Ciência da Informação, das regiões norte, nordeste e centro-oeste, que se dispuseram a colaborar com a pesquisa.

\section{REFERÊNCIAS}

ALCADIPANI, R. Academia e a fábrica de sardinhas. Organizações \& Sociedade, Salvador, v. 18, n. 57, p. 345-348, 2011.

ALCADIPANI, R. Resistir ao produtivismo: uma ode à perturbação acadêmica. Cadernos EBAPE. BR, Rio de Janeiro, v. 9, n. 4, p. 1174-1178, 2011.

ALVES, Rui. Publish or Perish. Portuguese Journal of Nephrology \& Hypertension, v. 28, p. 277-279, 2014.

ANDRADE, J. de S.; CASSUNDÉ, F. R. de S. A.; BARBOSA, M. A. C. Da liberdade à "Gaiola De Cristal": sobre o produtivismo acadêmico na pós-graduação. Perspectivas em Gestão \& Conhecimento, n. 1, v. 9, p. 169-197, 2019.

ASSOCIAÇÃO DOS DOCENTES DA USP. Dossiê "Produtivismo acadêmico": (ainda é) tempo de reagir. Revista Adusp, São Paulo, n. 60, maio 2017.

BARDIN, L. Análise de Conteúdo. 3. ed. São Paulo: Edições 70, 2011.

BIANCHETTI, L. Os dilemas do coordenador de programa de pós-graduação: Entre o burocrático-administrativo e o acadêmico-pedagógico. In: BIANCHETTI, L; SGUISSARDI, V. Dilemas da pós-graduação em educação: gestão e avaliação. Campinas: Autores Associados, 2009.

BIANCHETTI, L.; MACHADO, A. M. N. Trabalho docente no stricto sensu: publicar ou morrer. A intensificação do trabalho docente: tecnologia e produtividade. Campinas, SP, Papirus, 2009.

BIANCHETTI, L.; VALLE, I. R. Produtivismo acadêmico e decorrências às condições de vida/trabalho de pesquisadores brasileiros e europeus. Ensaio: Avaliação e Políticas Públicas em Educação, Rio de Janeiro, v. 22, n. 82, p. 89-110, jan./mar. 2014.

BORSOI, I. C. F. Trabalho e produtivismo: saúde e modo de vida de docentes de instituições públicas de Ensino Superior. Cadernos de Psicologia Social do Trabalho, v. 15, n. 1, p. 81100, 2012.

BOSI, A. de P. A precarização do trabalho docente nas instituições de ensino superior do Brasil nesses últimos 25 anos. Educação \& Sociedade, Campinas, v. 28, n. 101, 2007.

CAFÉ, A. L. da P. O controle e a regularidade na produção e na difusão de conhecimento no campo científico interdisciplinar. 2017. 322f. Tese (Doutorado Multilnstitucional e Multidisciplinar em Difusão do Conhecimento) - Universidade Federal da Bahia, Salvador, 2017. 
CAFÉ, A. L. da P.; RIBEIRO, N. M.; PONCZEK, R. L. A fabricação dos corpos dóceis na pósgraduação brasileira: em cena o produtivismo acadêmico. Encontros Bibli: revista eletrônica de biblioteconomia e ciência da informação, v. 22, n. 49, p. 75-88, 2017.

CAMARGO JR, K. R. de. Publicar ou perecer, ou perecer por publicar (em excesso)? 2014.

CURTY, R. G. Produção intelectual no ambiente acadêmico. Renata Curty, 2010.

FERREIRA, C. G.; MIRANDA, A. V. de; GURGEL, C. R. M. Consequências do produtivismo acadêmico para a vida docente. Revista Brasileira de Administração Política, v. 8, n. 2, p. 63, 2016.

GODOI, C. K.; XAVIER, W. G. O produtivismo e suas anomalias. Cadernos EBAPE.BR, v. 10, n. 2, p. 456-465, 2012.

GUILL, T. F.; ZANFERARI, T.; ALMEIDA, M. de L. P. de. Produtivismo acadêmico, suas origens e consequências. In: SEMINÁRIO INTERNACIONAL DE REPRESENTAÇÕES SOCIAIS, SUBJETIVIDADE E EDUCAÇÃO, 4., SIRSSE - Seminário Internacional sobre Profissionalização Docente, 6., SIPD/CÁTEDRA UNESCO, 2017, Curitiba, SC. Produtivismo Acadêmico, suas origens e consequências, 2017. p. 18071-18086.

HOSTINS, R.C.L. Os Planos Nacionais de Pós-graduação (PNPG) e suas repercussões na Pósgraduação brasileira. Perspectiva, Florianópolis, v. 24, n. 1, p. 133-160, 2006.

KUENZER, A. Z; MORAES, M. C. M. de. Temas e tramas na pós-graduação em educação. Educação \& Sociedade, Campinas, v. 26, n. 93, p. 1341-1363, set./ dez. 2005.

KUHLMANN JR., M. Produtivismo acadêmico, publicação em periódicos e qualidade das pesquisas. Cadernos de Pesquisa, n. 158, v. 9, p. 838-855, 2015.

LEITE, J. L. Publicar ou perecer: a esfinge do produtivismo acadêmico. Revista Katálysis, Florianópolis, v. 20, n. 2, p. 207-215, 2017.

MACHADO, A. M. N. Políticas que impedem o que exigem: dimensões controvertidas na avaliação da pós-graduação brasileira. Universidade e Sociedade, v. 39, p. 137-149, 2007.

MATTOS, P. L. C. L. de. Nós e os índices: a propósito da pressão institucional por publicação. Revista de Administração de Empresas, v. 48, n. 2, p. 144-149, 2008.

MOREIRA, A. F. A. A Cultura da performatividade e a avaliação da Pós-Graduação em Educação no Brasil. Educação em Revista, v. 25, n. 3, p. 23-42, 2009.

NÓVOA, A. O Regresso dos professores. In: Conferência desenvolvimento profissional de professores ao longo da vida. Lisboa, Portugal, 2007.

PATRUS, R.; DANTAS, D. C.; SHIGAKI, H. B. O produtivismo acadêmico e seus impactos na pós-graduação stricto sensu: uma ameaça à solidariedade entre pares? Cadernos EBAPE. BR, v. 13, n. 1, p. 1-18, 2015.

PAULA, M. de F. C. de. Políticas de avaliação da educação superior e trabalho docente: a autonomia universitária em questão. Universidade e Sociedade/Sindicato Nacional dos Docentes das Instituições de Ensino Superior, São Paulo, v. 21, n. 49, p. 51-61, 2012. 
PIMENTA, A. G.. (Des)caminhos da pós-graduação brasileira; o produtivismo acadêmico e seus efeitos nos professores pesquisadores. Tese do doutorado em Educação da Universidade Federal da Paraíba (UFPB), 2015.

REGO, T. C. Produtivismo, pesquisa e comunicação científica: entre o veneno e o remédio. Educação e Pesquisa, v. 40, n. 2, p. 325-346, 2014.

RIBEIRO, C. V. dos S.; LEDA, Denise Bessa; SILVA, Eduardo Pinto e. A expansão da educação superior pública e suas implicações no trabalho docente. Revista Educação em Questão, Natal, v. 51, p. 147-174, 2015.

ROSA, A. "Nós e os índices" - um outro olhar sobre a pressão institucional por publicação. Revista de Administração de Empresas, v. 48, n. 4, p. 108-114, 2008.

SAMPAIO, P. P. Ser (in)feliz na universidade: sofrimento/prazer e produtivismo no contexto da pós-graduação em Saúde Coletiva/Saúde Pública. 2016. Tese (Doutorado em Saúde Coletiva) - Universidade de Fortaleza, Fortaleza, 2016.

SANTOS, S. A. A naturalização do produtivismo acadêmico no trabalho docente. Revista Espaço Acadêmico, v. 10, n. 110, p. 147-154, 2010.

SGUISSARDI, V. Produtivismo acadêmico. In: OLIVEIRA, D. A.; DUARTE, A. M. C.; VIEIRA, L. M. F. (Org.). Dicionário de trabalho, profissão e condição docente. Belo Horizonte: Ed. UFMG, 2010.

SGUISSARDI, V.; SILVA JUNIOR, J. dos R. Trabalho intensificado nas federais: pós-graduação e produtivismo acadêmico. São Paulo: Xamã, 2009.

TREIN, E.; RODRIGUES, J. O mal-estar na academia: produtivismo científico, o fetichismo do conhecimento-mercadoria. Revista Brasileira de Educação, v. 16, n. 48, p. 769-792, 2011.

VELLOSO, J.; VELHO, L. M. L. S. Mestrandos e doutorandos no país: trajetórias de formação. Brasília: Coordenação de Aperfeiçoamento de Pessoal de Nível Superior, 2001. Disponível em: http://www.dominiopublico.gov.br/download/texto/me001615.pdf. Acesso em: 2 dez. 2015.

VIZEU, F.; MACADAR, M. A.; GRAEML, A. R. Produtivismo acadêmico baseado em uma perspectiva habermasiana. Cadernos EBAPE. BR, v. 14, n. 4, p. 984-1000, 2016.

VOSGERAU, D. S. R.; ORLANDO, E. de A.; MEYER, P. Produtivismo acadêmico e suas repercussões no desenvolvimento profissional de professores universitários. Educação \& Sociedade, Campinas, v. 38, n. 138, p. 231-247, 2017. Disponível em:

https://www.scielo.br/pdf/es/v38n138/1678-4626-es-ES0101-73302016163514.pdf. Acesso em: 10 mar. 2019.

WATERS, L. Inimigos da esperança: publicar, perecer e o eclipse da erudição. São Paulo: Editora da UNESP, 2006.

YAMAMOTO, O. H. et al. Produção científica e "produtivismo": há alguma luz no final do túnel? Revista Brasileira de Pós-Graduação, Brasília, v. 9, n. 18, 2012. 